\title{
Effect of Finite Element Mesh and Load Location on the Stress and Deflection of a Light Aircraft Metal Wing Structure
}

\author{
By Mostefa BourchaK ${ }^{1)}$ and Yousef DOBAH ${ }^{2)}$ \\ 1) Aeronautical Engineering Department, King Abdulaziz University, Jeddah, Saudi Arabia \\ ${ }^{2)}$ Mechanical Engineering Department-North Jeddah, King Abdulaziz University, Jeddah, Saudi Arabia
}

(Received April 4th, 2012)

\begin{abstract}
Using the Abaqus ${ }^{\circledR}$ Computer-Aided Engineering (CAE) and Finite Element Analysis (FEA) software package, this study aims to numerically simulate the effect of the aerodynamic lift load experienced by a light all-metal aircraft in flight. The objective is to find how much stress and deflection is accumulated under the design ultimate load and also to identify the critical components in the wing structure. The load profile is idealized as a uniformly distributed load over the wing. The wing components such as spars, ribs, skin and struts are initially composed using SolidWorks ${ }^{\circledR}$ and then imported using Abaqus ${ }^{\circledR} \mathrm{CAE}$ for stress and stiffness analysis. Various scenarios of load and geometry are analyzed and their results discussed. These scenarios include the choice of solid or shell elements of the components as well as the location of load concentration (pressure on the skin or direct load on the spar cap). Results show that for aircraft wing analysis purposes, the skin should be included in the analysis and the load should be applied on both the bottom and top surfaces. The meshing type is also found to have a greater effect on stress results than on deflection results.
\end{abstract}

Key Words: Structural Design, Structural Optimization, Lift, Finite Element Analysis, Deflection, Strength

\section{Introduction}

The use of finite element analysis (FEA) in light aircraft design has not been considered a regular choice by engineers and designers in this industry in the past due to the cost and complexity of FEA packages. Light aircraft designs were generally based on know-how, simple stress hand calculations and experience only. ${ }^{1-3)}$ However, with the current development and vast choice of FEA software packages (even free ones) it is becoming wiser to invest in these tools in order to achieve highly optimized and more cost effective products especially in light aircraft design where weight is an issue. ${ }^{4)}$ However, for inexperienced FEA users, modeling an FEA problem and interpreting results can have significant effects and can lead to dangerous misinterpretation of data. In a light aircraft, the main component is the wing structure which is mainly subjected to lift load and fuel weight. However, when simulating the load it is necessary to consider where the concentration of load should be. Hence, carrying out a structural test in the laboratory to confirm design can be misleading if the load is not applied correctly. Initially, the load profile is estimated spanwise using simplified techniques. ${ }^{5)}$ Then, simulation analysis is carried out on the wing using an FEA package with careful modeling of the boundary conditions, meshing type/intensity and load concentration surfaces. Of particular concern in the FEA modeling is the design of the FE mesh. ${ }^{6}$ This is found to have direct effect on aircraft conceptual design process and hence cost savings. ${ }^{7}$ FEA results can then highlight potential high stress and risk areas that need to be re-designed. ${ }^{8)}$ The process of

(C) 2013 The Japan Society for Aeronautical and Space Sciences iteration design can eventually lead to an optimized structure at the simulation stage ${ }^{9,10)}$ before manufacturing begins leading to potentially major cost and weight savings. ${ }^{11)}$ In this work, the effect on stress and deflection of applying the lift generated load in different forms is investigated. Generally, lift load is considered as a distributed load on the top surface of the wing for hand calculation purposes. However, in reality, lift is generated through aerodynamic pressure on the top and bottom surfaces. In addition, the type and form of meshing is also simulated and results discussed.

\section{3D CAD Wing Drawings}

All of the wing main structural components are drawn in SolidWorks ${ }^{\circledR}$ computer-aided design (CAD) software using the dimensions of a typical light aircraft having rectangular high wing, strut braced and constant chord. The aircraft considered in this investigation has a gross weight of $600 \mathrm{~kg}$ which is a typical weight for a two-seat metal light aircraft having a rectangular high wing with struts. However, the wing under investigation weighs approximately $22.8 \mathrm{~kg}$ according to CAD drawings and chosen material properties. Other wing properties are:

- Wing skin area (top + bottom + nose): 7.5 sq. $\mathrm{m}$

Wing airfoil (profile): NACA 650-18

Wing span: $9.1 \mathrm{~m}$

. Wing length from root to tip: $4 \mathrm{~m}$

Wing chord: $1.47 \mathrm{~m}$ (0.95 m without flaps)

- Wing aspect ratio: 6.2

The wing components are then assembled to produce the model shown in Fig. 1. The chosen wing model is made of a 

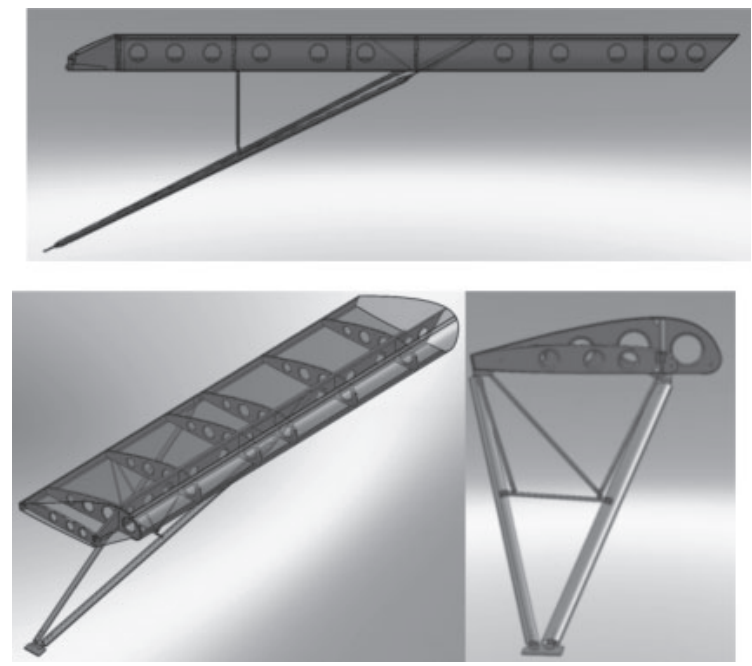

Fig. 1. Different views of the 3D CAD wing model.

main spar with lightening holes, rear channel, seven ribs in the form of nose/rear ribs, struts, upper skin and lower skin. The spar is located $0.22 \mathrm{~m}$ from the leading edge and the ribs are placed $68 \mathrm{~cm}$ apart except the first rib which is placed $24 \mathrm{~cm}$ from the root and the two center ribs which are $40 \mathrm{~cm}$ apart. This wing is mainly made out of aluminum alloy with attachment parts made of steel.

\section{Finite Element (FE) Model Preparation}

The wing structure is analyzed using the Abaqus ${ }^{\circledR}$ computer-aided engineering (CAE) FEA software. This is a program that uses the finite element (FE) method as a numerical solution procedure to solve various simple and complicated engineering problems. In this case the problem is a simple mechanical (static) one that consists of geometry, load and boundary conditions. This problem is modeled in Abaqus ${ }^{\circledR}$ CAE as follows.

\subsection{Geometry and material}

- We import the 3D assembly drawings into Abaqus ${ }^{\circledR} \mathrm{CAE}$ and transform them to shell and/or solid parts.

- The materials used are aluminum alloy 6061-T6 with a 68.9 GPa modulus of elasticity, 0.33 Poisson's ratio and $0.0027 \mathrm{~g} / \mathrm{mm}^{3}$ density, and steel with $205 \mathrm{GPa}$ modulus of elasticity, 0.29 Poisson's ratio and $0.00785 \mathrm{~g} / \mathrm{mm}^{3}$ density.

- Parts are meshed independently to reach optimum element distribution. Due to parts shape complexity and in order to achieve the best possible meshing, each part is meshed independently. The meshing suitability is optimized after many solution iterations.

- Parts interaction is defined as tied (fixed).

\subsection{Boundary conditions}

- The joints of the struts, jury strut and fuselage fixation are chosen as fixed support.

\subsection{Load application}

Generally, lift distribution is not uniformly distributed spanwise. However, given the small size of the constant-
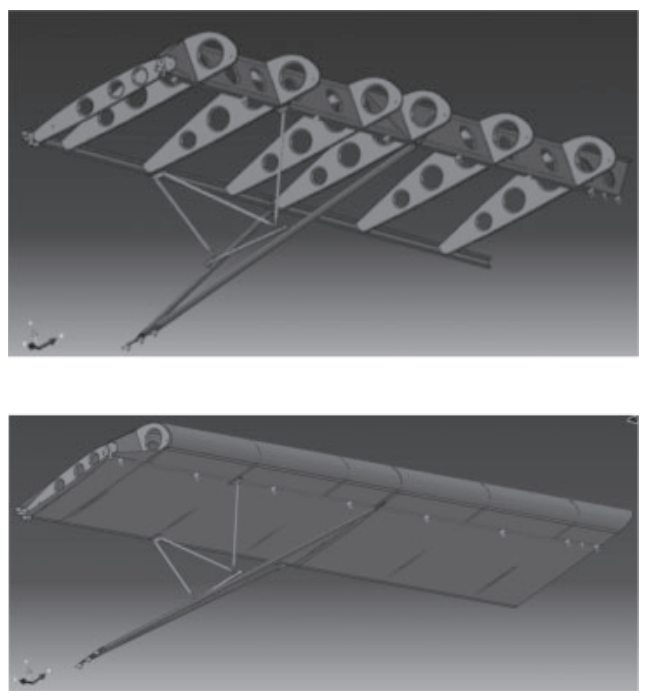

Fig. 2. Load configuration of case 1 (top: without skin; bottom: with skin).

chord rectangular wing and its high wing configuration (wings mounted on the upper fuselage that generate some lift), the load profile is assumed to be uniformly distributed for simplified calculation and because this study is more concerned about the effect of FE meshing and location of applied load on wing stress and deflection than producing accurate results. However, for more accurate calculations and representation of actual wing behavior, the spanwise load distribution is slightly elliptical with less lift produced at the fuselage region. In the chordwise direction, pressure coefficient graphs should be used to determine load distribution. For this study, as well as various forms of meshing, three scenarios of applied load simulation are investigated. Note that in real flight there is a different load configuration at the root and tip due to vortices which is not being simulated here.

- Case 1: Distributed lift pressure is applied on the wing spar lower cap only. This load configuration is chosen because the position of the spar is located roughly where the center of pressure is estimated to be. An example of this case is shown in Fig. 2.

- Case 2: Distributed lift pressure is applied on the wing's bottom skin. This load configuration simulates a typical wing structural test that is usually carried out in the laboratory for certification purposes or confirmation of hand calculations/FEA.

- Case 3: Distributed lift pressure is applied on the bottom and upper skins of the wing. Note that in real flight there is a different load configuration at the leading and trailing edges due to vortices. This load configuration is more representative of the real life scenario where the lift generated from the upper skin is twice the lift from the bottom skin.

All the applied loads are taken to be $1,500 \mathrm{~kg}$, which is converted to a force equal to $14.88 \mathrm{kN}$. This load is also converted, depending on the investigated load application case, to a uniformly distributed pressure as shown in Table 1. 
Table 1. Wing load simulations.

\begin{tabular}{lll}
\hline \multicolumn{1}{c}{ Load case } & Area $\left(\mathrm{mm}^{2}\right)$ & Pressure $\left(\mathrm{N} / \mathrm{mm}^{2}\right)$ \\
\hline Case 1: & & \\
Spar's lower cap & 95492.3 & 0.1558 \\
Case 2: & 3194100 & 0.0046 \\
$\quad$ Wing's bottom skin & & \\
$\begin{array}{l}\text { Case 3: } \\
\text { Wing's bottom and top skins }\end{array}$ & 6388200 & $\begin{array}{l}\text { Bottom }=0.0015 \\
\text { Top }=0.0031\end{array}$ \\
\end{tabular}
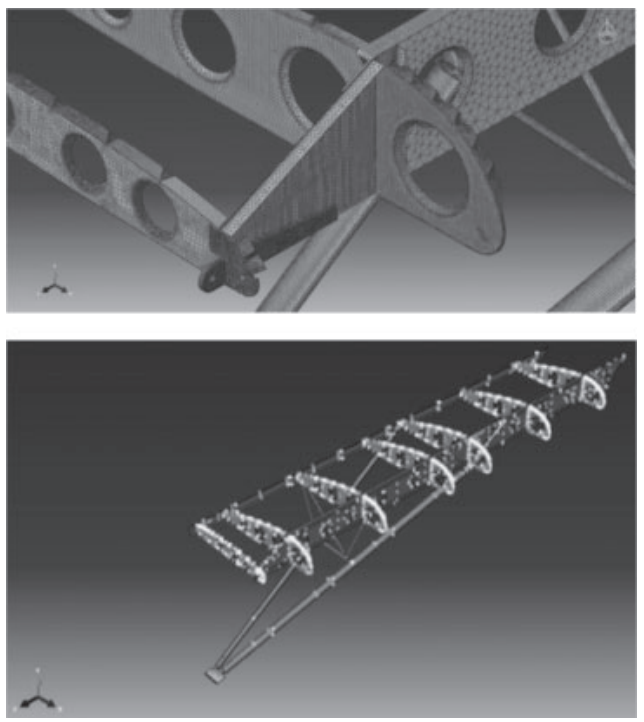

Fig. 3. Model 1: Meshing type (top) and components interaction (bottom).

\section{4. $\quad$ FE meshing}

\subsubsection{FE meshing model 1}

In this model, parts are designed as being solid parts. The model is also without skin and the meshing element type is a linear tetrahedron element with four nodes as shown in Fig. 3. Figure 3 also shows the interaction between wing components.

\subsubsection{FE meshing model 2}

Parts in this model are also chosen to be solid parts as in model 1 but with the addition of bottom and top skins. The meshing element type is a linear tetrahedron with four nodes and linear bricks elements with eight nodes for the skin as shown in Fig. 4. Figure 4 also shows the interaction between the wing components.

\subsubsection{FE meshing model 3}

In this case, most parts are chosen to be shell elements except for the jury struts and their fixations due to their shape complexity. Meshing element types are shell quadratic quadrilateral elements with eight nodes, shell quadratic triangle elements with six nodes, solid quadratic tetrahedron elements with ten nodes and solid quadratic triangular prism elements with 15 nodes as shown in Fig. 5. Figure 5 also shows the interaction between the wing components.

\subsubsection{FE meshing model 4}

In the final model, parts are meshed as in model 3 but with the addition of bottom and top skins. The meshing elements
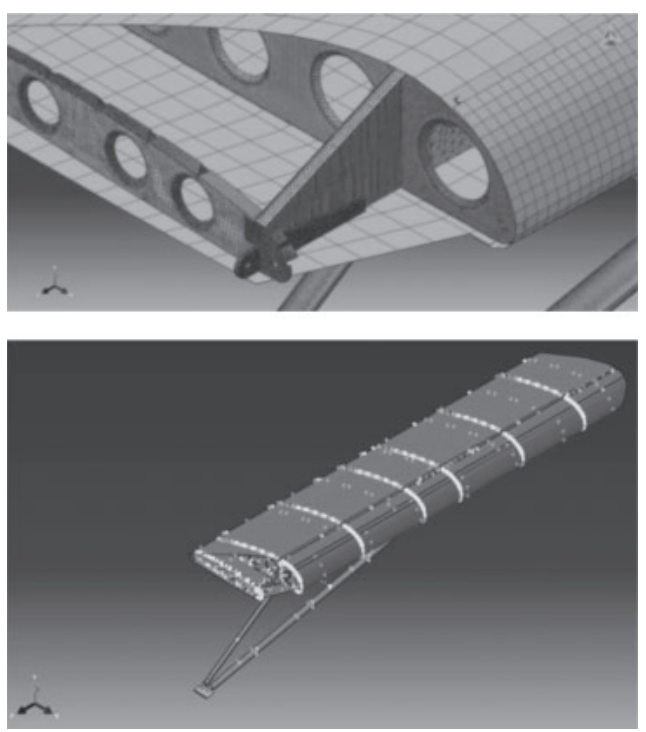

Fig. 4. Model 2: Meshing type (top) and components interaction (bottom).
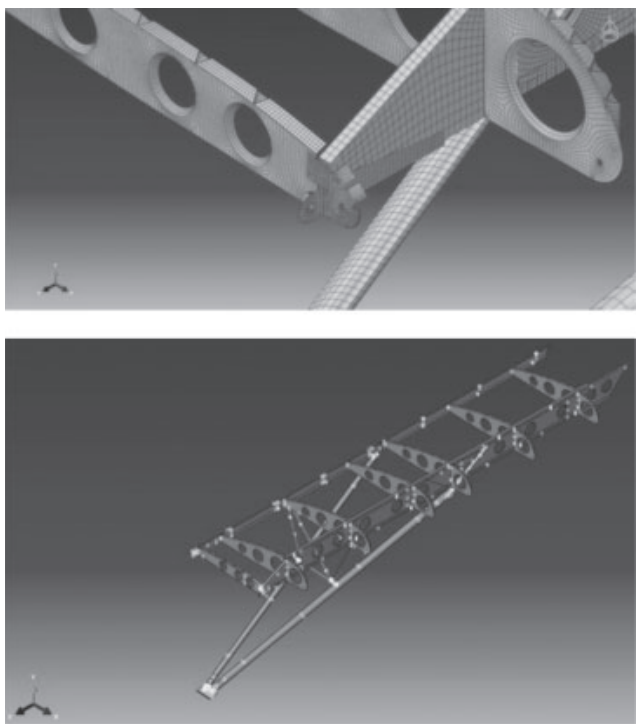

Fig. 5. Model 3: Meshing type (top) and components interaction (bottom).

types are shell quadratic quadrilateral elements with eight nodes, shell quadratic triangle elements with six nodes, solid quadratic tetrahedron elements with ten nodes and solid quadratic triangular prism elements with 15 nodes as shown in Fig. 6. Figure 6 also shows the interaction between the wing components.

\section{Results and Analysis}

Figures 7 to 10 show the resulting maximum Von Mises stresses and wing tip deflections for each of the tested FE models under one of the three load configurations: pressure on the spar's lower cap, pressure on the bottom skin only and pressure on both the bottom and top skins.

Figure 7 shows that the FE models without skin (i.e., models 1 and 3) yielded very high deflections as expected. 

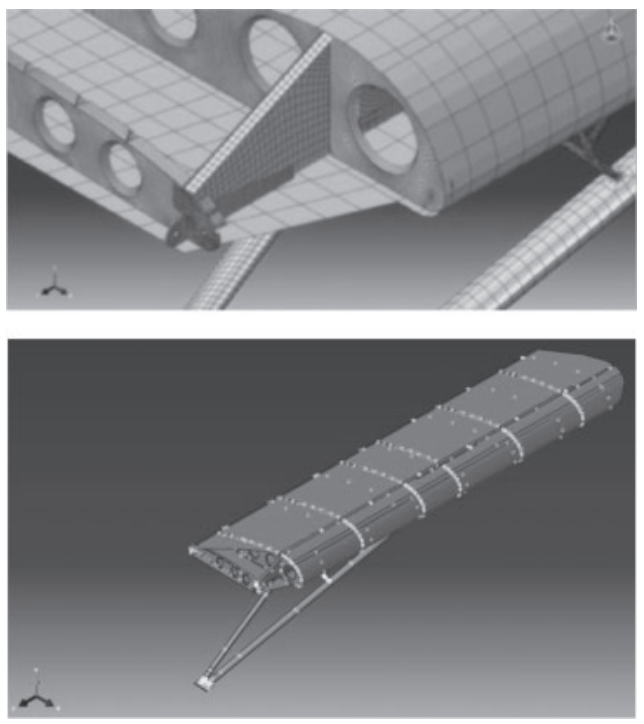

Fig. 6. Model 4: Meshing type (top) and components interaction (bottom).

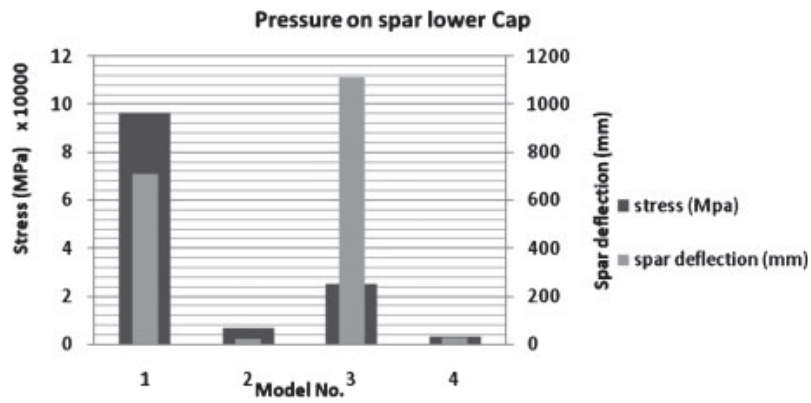

Fig. 7. Maximum stresses and deflections when load is applied as pressure on the spar's lower cap.

Part of this deflection is due to the unsymmetrical wing bending resulting from the load being applied at the spar lower cap and not necessarily at the wing shear center. This caused the wing to deform to unrealistically high deflection values relative to the size of the wing being studied as shown by the FEA results (between 0.7 and $1.12 \mathrm{~m}$ ). The results from Fig. 7 also show that FE model 1 yielded significantly larger stresses $(96 \mathrm{GPa})$ relative to the other models especially those with skins. For this reason, it is obvious that simulation using the wing skeleton would only lead to significant errors. Additionally, results from Fig. 7 show that maximum stresses and deflection for FE models with skin are relatively similar and realistic. Consequently, FE models without skins (models 1 and 3) were eliminated from the analysis of the second and third load cases. Figure 8 shows the results of models 2 and 4 viewed without models 1 and 3 . Figure 9 shows a summary of stress and deflection results when the applied load is on the bottom skin only (FE models 2 and 4). In this case the wing deflection seems to be absorbed by the bottom skin which reduces the deflection of the spar as shown in Fig. 9. This effect is shown clearly in a shell model which consists of more flexible elements than a solid model. Figure 9 also indicates that the inclusion of shell

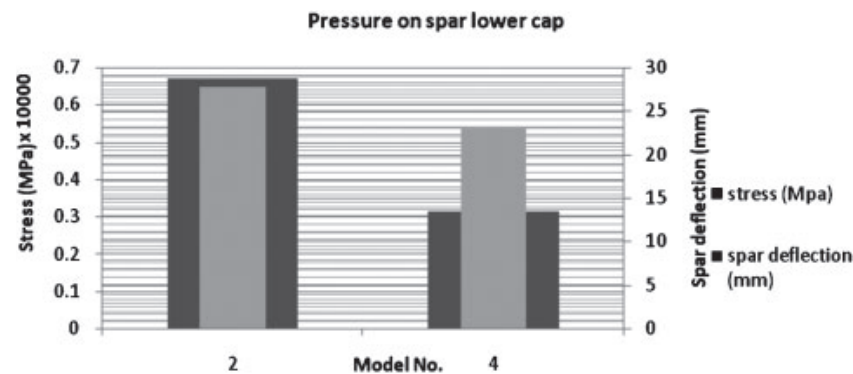

Fig. 8. Maximum stresses and deflections when load is applied as pressure on the spar's lower cap (models 2 and 4).

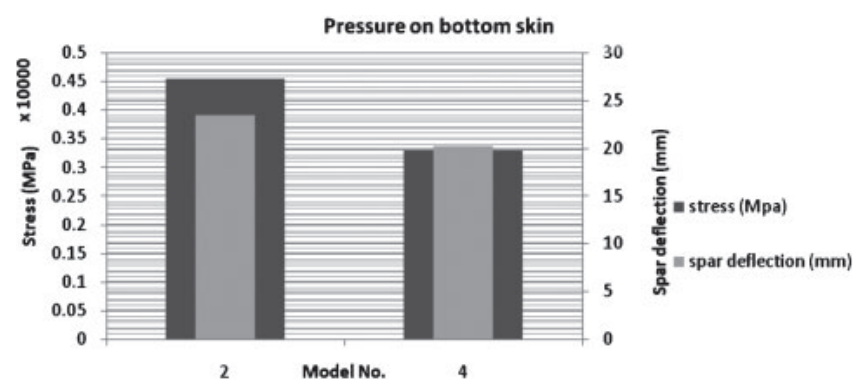

Fig. 9. Maximum stresses and deflections when load is applied as pressure on the bottom skin only.

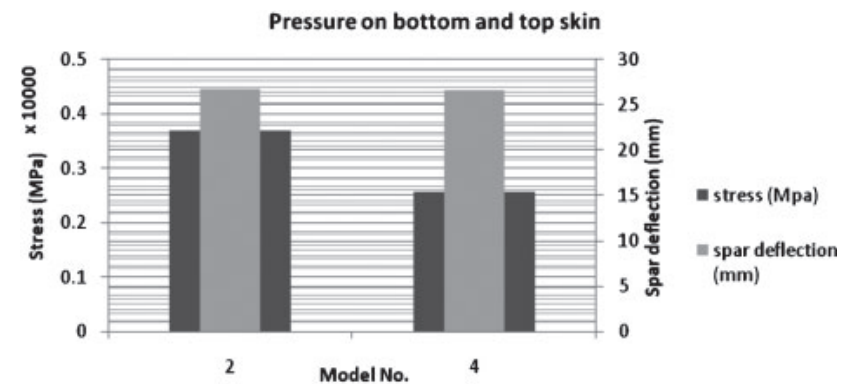

Fig. 10. Maximum stresses and deflections when load is applied as pressure on both the bottom and top skins.

elements caused the deflection to decrease slightly and the stress to decrease significantly.

On the other hand, when the load is distributed between the bottom and top skins, the difference between the deflection results of the second and the fourth FE models is smaller but with some difference in stress results remaining as shown in Fig. 10. Compared to when the load is applied on the bottom skin only as with a real life ground structural wing test, the deflection increased slightly but the stress decreased, indicating that the ground structural test should be considered to be a conservative test when it comes to stress values. However, the load case 3 configuration is more realistic of what happens during flight and is therefore considered to yield the most accurate results which would require less wing material as compared to designs based on ground structural wing test results. Figure 10 also indicates that the choice of shell or solid elements does not affect deflection whereas it affects stress.

Finally, an example of a component that had high stress concentration is shown in Figs. 11 and 12. In Fig. 11, the 
central rib just above the strut fixation on the wing experienced plastic deformation (279.3 MPa in max. stress) which is not critical to the wing integrity but it should be reinforced at the expense of weight reduction in other low stress ribs or it should be designed using a different material to the other ribs. In a similar way, and perhaps with the inclusion of simple optimization algorithms, FEA results can help designers of light aircraft optimize their product significantly in order to reduce weight and hence cut the cost. Figure 12 shows the case where the stress is highest at the wingfuselage attachment component.

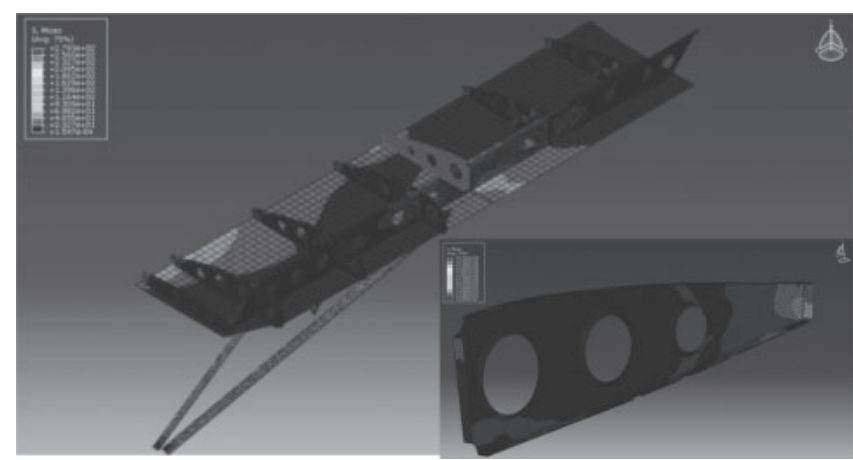

Fig. 11. FEA results showing plastic deformation in the wing with a rear center rib.

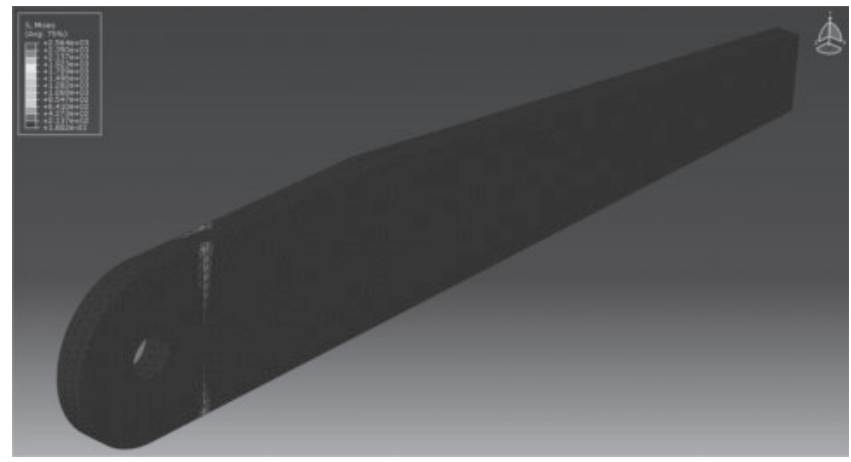

Fig. 12. FEA results showing plastic deformation in the wing-fuselage attachment component.

\section{Conclusions}

Four FE models based on mesh variations of light aircraft wing structures were investigated under three lift load cases. The main difference in the FE mesh was the choice of solid or shell types with two FE models being analyzed with skin on and two others without skin. Results indicated that relying on the analysis of a skeleton structure should be avoided, i.e., skin should be included in the analysis. Moreover, the results showed that FE mesh modifications can lead to some variation in stresses but not in deflection. In terms of load application position on the wing, applying lift pressure load as experienced by an aircraft wing in flight should lead to more accurate results, whereas the application of lift distributed load on the bottom skin as with the case of ground structural test is more conservative in terms of stress values. In addition, FEA results can easily indicate the wing parts that may experience stresses beyond the materials' allowable levels (yield strength or ultimate strength). The results demonstrate that using FEA packages for early design checks not only leads to weight savings but also helps designers achieve safer components in critical areas such as the aircraft wing structure.

\section{References}

1) Hiscocks, R. D.: Design of Light Aircraft, DAR, Vancouver, 1995.

2) Fielding, J. P.: Introduction to Aircraft Design, Cambridge University Press, Cambridge, 1999.

3) Heintz, C.: Flying on Your Own Wings, 2nd Edition, Trafford Publishing, Victoria, BC, Canada, 2010.

4) Alsaie, A. M., Klindera, B. E., Love, M. H. and Rogers, W. A.: Optimization of Aircraft Structures Using STARSTRUC, SAE Technical Paper Series, 871049, 1987.

5) Schrenk, O.: A Simple Approximation Method for Obtaining the Spanwise Lift Distribution, NACA, TM 948, 1940.

6) Dolsak, B. and Muggleton, S.: The Application of Inductive Logic Programming to Finite Element Mesh Design, Inductive Logic Programming, Academic Press, London, 1992.

7) Sohaib, M.: Parameterized Automated Generic Model for Aircraft Wing Structural Design and Mesh Generation for Finite Element Analysis, IET, Linköping University, Linköping, 2011, p. 66.

8) Logan, D. L.: A First Course in the Finite Element Method, 5th Edition, CL-Engineering, Stanford, 2011.

9) Chintapalli, S., Elsayed, M. S. A., Sedaghati, R. and Abdo, M.: The Development of Preliminary Structural Design Optimization Method of an Aircraft Wing-box Skin-stringer Panels, Aerospace Sci. Technol., 14 (2010), pp. 188-198.

10) Guo, S: Aeroelastic Optimization of an Aerobatic Aircraft Wing Structure, Aerospace Sci. Technol., 11 (2007), pp. 396-404.

11) James, P., Krishna, D. M., Kotresh, G. and Varughese, B.: Finite Element Analysis of Inter Spar Ribs of Composite Wing of Light Transport Aircraft against Brazier Load, National Conference on Scientific Achievements of SC \& ST Scientists \& Technologists, Bangalore-17, 2009. 